Proceedings of the Annual Scientific Meeting of the Society held at Stoke Mandeville Hospital, Aylesbury, 27th to 29th July 1967.

\author{
PART I \\ ORGANISATION OF SPINAL UNITS
}

\title{
HISTORY OF THE NATIONAL SPINAL INJURIES CENTRE, STOKE MANDEVILLE HOSPITAL, AYLESBURY
}

\author{
By Sir Ludwig Guttmann, C.B.E., M.D., F.R.C.P., F.R.C.S.
}

Creation and Development of the Centre during World War II. It is an accepted fact that any war, while creating devastation and great suffering to mankind, nevertheless brings within its wake advances in the medical field. In no medical subject could this be more true than in that of traumatic paraplegia and tetraplegia, which throughout the centuries was one of the most depressing and indeed neglected subjects in medicine. Even in the early stages of World War II, when the modern conception of rehabilitation of the disabled was generally accepted for amputees and other crippling disabilities, spinal paraplegia was not included in this concept. I recall a Symposium on Rehabilitation following Injuries of the Central Nervous System held in November I94I in the Neurology Section of the Royal Society of Medicine where four speakers discussed rehabilitation following brain injuries and one following peripheral nerve lesions. The subject of spinal paraplegia was hardly mentioned. Yet a fundamental step forwards in a new approach to the management of spinal paraplegia was taken in Great Britain by the Peripheral Nerve Committee of the Medical Research Council under the leadership of Dr. George Riddoch, Neurological Consultant to the British Army, Ministry of Health and Ministry of Pensions, when it was decided to congregate spinal cord casualties in special units. For it was generally agreed that the possibilities for a systematic study of the many problems concerned with the treatment of spinal paraplegics throughout all stages was infinitely more favourable in such a unit than when these patients lay scattered in general medical or surgical wards, from which, as a rule, they were transferred to chronic wards or homes for incurables. Even if they were admitted to neurological, neurosurgical, orthopaedic or urological units, the facilities available were limited to specialised problems and short-term treatment only. These units were so busy with the management of many other afflictions in their respective specialities that, as a rule, it was quite impossible for both the medical and nursing staff to give paraplegics, let alone tetraplegics, that meticulous care and attention which these patients need day and night, especially during the acute stages. However, the first spinal units did not prove satisfactory as they were attached to neurosurgical or orthopaedic units and no one member of their staff devoted more than a part of his time to the care and management of spinal injury patients. In those days it had not been generally recognised that in order to prevent spinal units from becoming merely an accummulation of doomed and demoralised cripples certain conditions were indispensable:

I. The supervision of such a unit by an experienced surgeon or physician of I 
whatever speciality who was prepared to devote his full time to the work, in order to organise and supervise the many aspects of management and, in particular, to correlate the sometimes conflicting interests and approach of the various medical and surgical specialists concerned, in particular, with the early treatment of these patients.

2. Adequate technical facilities for the specialised care and rehabilitation of these long-term patients, including physiotherapy, occupational therapy and pre-vocational training to promote independence and return to social and professional activities.

3. Nursing and auxiliary staff sufficient in number to cope with the many details of management and, in particular, avoidance of the usual practice of changing nursing staff from one department to another at short intervals.

4. Arrangements for adequate domestic and industrial resettlements for paraplegics.

In I 943 it was contemplated to set up a spinal unit at the Ministry of Pensions Hospital, Stoke Mandeville, in Aylesbury, as one of the medical preparations for the Second Front, as many more spinal cord casualties were anticipated. With the opening of this unit on Ist Februaty 1944, a new era began for these spinal cord sufferers. The basic principle of the new approach was the idea to provide for the spinal paraplegic and tetraplegic patients a comprehensive service from the start of their injury or disease and throughout all stages to rescue these men and women from the human scrap-heap and to return them, in spite of their profound disability, to the community as useful and respected citizens. Two groups of patients were admitted:

I. Those in the acute stages of paraplegia following gunshot injuries, fracturedislocations and transverse myelitis. These patients were of particular importance to prove that it was in fact possible to avoid those complications which, throughout the ages, were considered as inevitable and the causes of the paraplegic's early death, namely sepsis, due to pressure sores and ascending urinary infection leading to renal deficiency. It may be noted that many of these patients arrived with associated injuries to other parts of the body. In due course, the number of paraplegics and tetraplegics admitted immediately or within the first few days after injury has increased immensely since it was proved, without any shadow of doubt, that pressure sores can be altogether avoided, and in a very high percentage the same also applies to the prevention of urinary infection.

2. Those in later stages of paraplegia suffering from many complications as a result of incompetent initial treatment, lack of proper facilities, or sheer neglect. Their condition was often extremely serious, demanding greatest vigilence and prolonged intensive efforts on the part of all concerned with their management to restore them both physically and mentally.

Radical changes in the medical and psychological approach to the problem of spinal paraplegia as a whole were introduced, and as in any pioneer work in medicine, dogmas and many prejudices had to be overcome. I still recall the question that was put to me with almost monotonous regularity by visitors in the first two years of our work: 'Is it really worth while?' It was quite unorthodox in those days to reject the conventional methods of recumbancy and immobilisation of traumatic paraplegics in plaster casts and plaster beds, as well as hasty operative 
procedures such as laminectomy and open reduction as initial treatment of the broken spine, and replacing them by new methods aimed at the mobilising of the natural forces of repair and readjustment. It was a new approach to both medical and nursing staff to teach that bedsores resulting in osteomyelitis and sepsis or infection of the paralysed bladder resulting in ascending infection and renal deficiency are by no means inevitable consequences of spinal paraplegia, but that those complications could, by introducing new methods of management, not only be controlled but altogether prevented. Above all, it was quite revolutionary to teach and impress on the authorities of medical and social services, in particular the Ministry of Labour and Housing Authorities, that the mere fact that a person was a paraplegic did not justify care in one of the institutions for 'incurables', but that in spite of his severe physical handicap, rehabilitation to a useful life and employment was possible in the great majority of cases. In this connection the first experiment to prove that paraplegics could work side by side and in competition with able-bodied workers was carried out with our first six rehabilitated paraplegic ex-servicemen at the end of 1944 .

It was also during the war that sport and regular work were introduced as essential parts in the medical treatment of these patients which, in due course, proved so very successful for their physical, psychological and social rehabilitation.

Post-war Development of the Unit into a National Centre. Already at the end of the war the number of beds of the unit was gradually increased to IOO as several of the original spinal units were dissolved and their patients transferred to Stoke Mandeville, and after the war the number of civilian paraplegic men, women and children steadily increased. By I95I, when Stoke Mandeville Hospital was taken over by the National Health Service, the unit had a compliment of 160 beds. These were increased in due course to I95 beds and the unit was designated as a National Centre, admitting patients from all parts of the United Kingdom. The patients are accommodated in six male, two female and one children's wards. Thanks to a grant of $£ 35,000$ from the 'Sir William Coxon Trust', a special annexe for children was built, indeed a great improvement for their accommodation and management.

As a result of a memorandum which I submitted to the Ministry of Health emphasising the great need for hostels in the proximity of spinal units for tetraplegics and other severely handicapped spinal cord sufferers who, for one reason or another, cannot be accommodated in their own homes, a pilot scheme of 30 beds was agreed, and this hostel was opened last year. It is connected to a workshop which enables the residents to carry out some remunerative work under sheltered conditions. Thus the Centre has now a total of 225 beds.

With the growth of the Centre the facilities of auxiliary services were also greatly increased. This applied to physiotherapy, occupational therapy and vocational training as well as school education for the children. Moreover, the facilities for sport and recreation were also greatly improved by the building of a recreational hall where training in indoor archery and table tennis could be carried out and also by the building of a large indoor swimming-pool.

The medical staff of this centre consists of a clinical director (Dr. J. J. Walsh, after my retirement in 1966), three consultants, a senior registrar and four junior grades. It also has its own records department, secretarial staff, welfare officer 
and almoner. Since I954 the Centre has had its own research department, consisting of a biochemical and physiology laboratory with a biochemist, technician and senior research assistant carrying out research work in co-operation with the clinical staff under my direction.

For the 225 patients (including the 30 residents of the hostel) there is a nursing staff strength of 163 , comprised of all grades, including student nurses and orderlies.

In addition to the 225 patients at the Centre and its Hostel, there are several auxiliary units affiliated to and medically guided by the N.S.I.C.:

(I) Spinal Unit at the Star and Garter Home for Ex-servicemen, Richmond, Surrey, set up in 1946 ( 24 beds).

(2) Chaseley Home, Eastbourne, for paralysed Ex-servicemen, started in 1946 (35 beds).

(3) Duchess of Gloucester House, Isleworth, Middlesex. This is a hostel with 78 beds ( 72 male and 6 female) opened in 1949 by the former Minister of Pensions and Minister of Labour for those paraplegics who are able and willing to take up full employment outside the hostel.

Advantages of a Spinal Unit as part of a General Hospital. For some years it has been argued whether a spinal centre should be part of a general hospital or a specialised hospital. It was feared that a spinal unit of larger size in a general hospital might be a hindrance to the development of other specialities. The Stoke Mandeville Centre has proved beyond all shadow of doubt that a centre, even of this size which, as a national institution, has served the whole country for many years, has been no detriment to other medical or surgical specialities in a general hospital. On the contrary, for those specialities serving the local and regional population, such as medical, surgical, rheumatic, paediatric, plastic surgery, geriatric units, etc., the existence of this centre, far from being a hindrance, has afforded facilities which these units have been able to utilise most advantageously for their own purposes. On the other hand, the spinal centre has been using the facilities of the general hospital such as X-ray department, operating theatre, pathology laboratory, etc., as any other unit and has enjoyed throughout the years the close co-operation with the consultants of other units who have been readily available if the need arose. Therefore, from all our experience, it can be concluded that the setting-up of a spinal centre in a general hospital, as a specialty of its own, represents an ideal solution.

Statistics on the Clinical Work since 1944. More than 4000 paraplegics and tetraplegics have been treated at this centre. As already pointed out, the turnover of both in-patient and out-patients has steadily increased since Stoke Mandeville Hospital was taken over by the National Health Service and Table I shows the turnover of patients from 1952 to I964. The majority of patients are admitted by road or rail, but in recent years transport by helicopter, especially of cervical patients and those associated with other injuries, has greatly increased, and indeed proved a life-saving measure in some of these patients. Moreover, patients from abroad, in particular service personnel of the British Forces, who sustained traumatic spinal cord lesions overseas, have arrived at the Centre within 48 hours of injury from as far afield as Germany, Aden and Singapore. Needless 
TABLE I

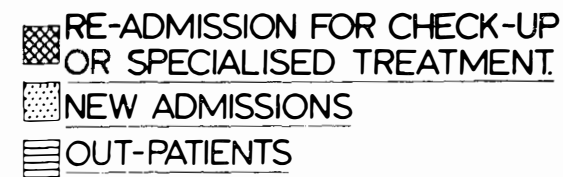

2000

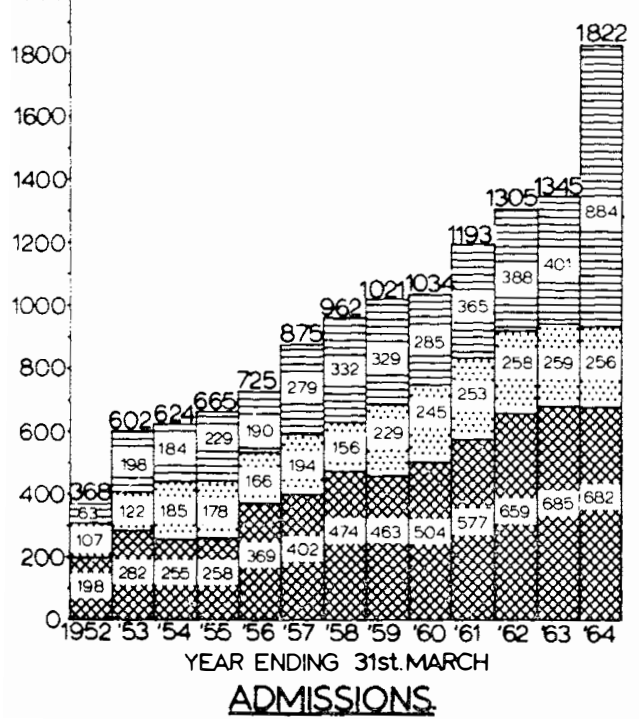

UDISCHARGED

-DEATHS

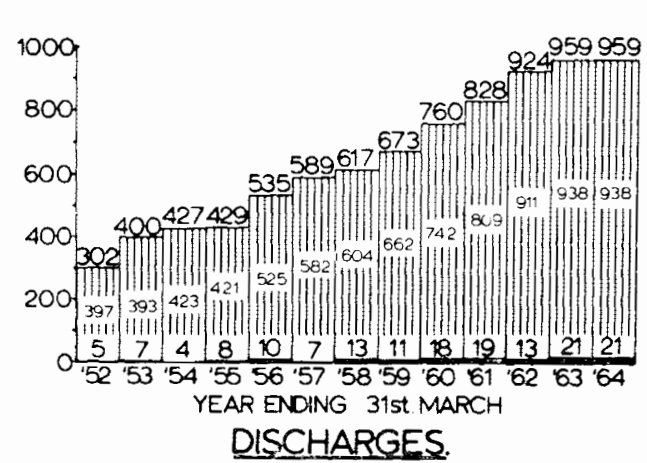

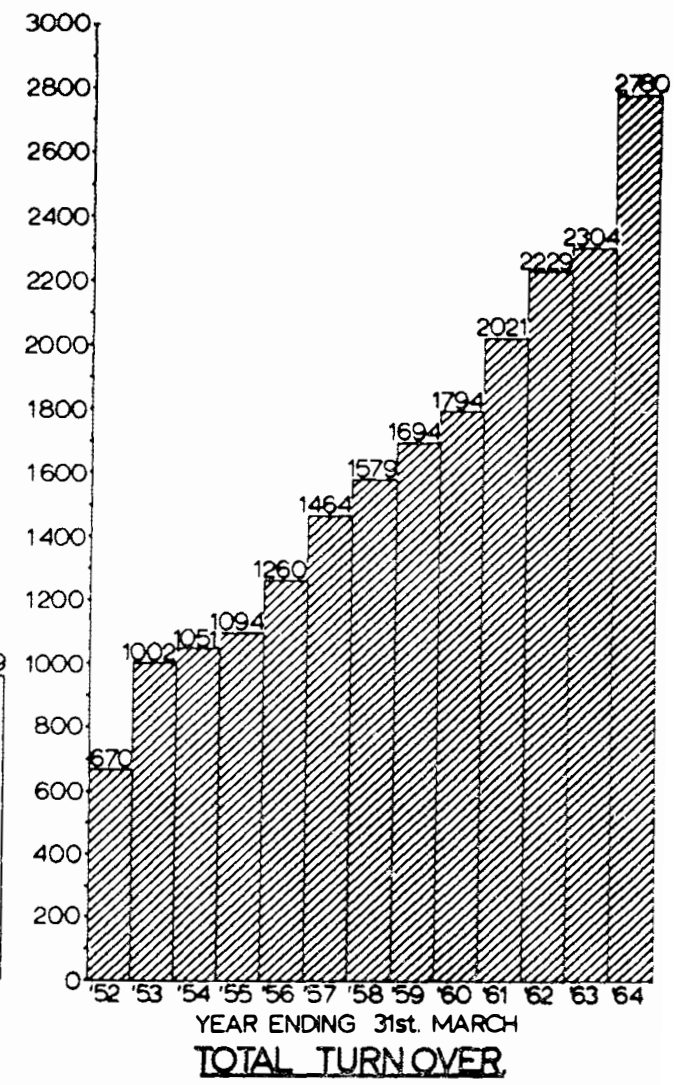


TABLE II

National Spinal Injuries Centre, Stoke Mandeville HospitalAnalysis of 3000 Cases

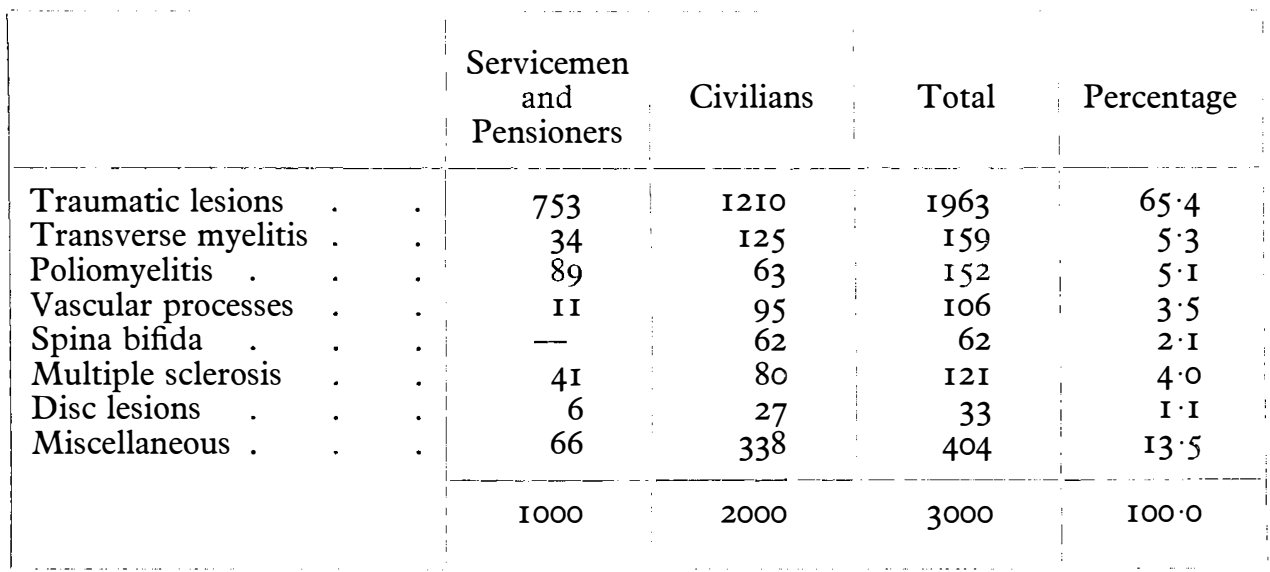

to say how this improved transport has not only saved lives but prevented many complications.

The clinical work of the Centre was analysed on the first 3000 cases admitted by May 1963 divided in ex-service personnel and civilians. From the statistics it is clear that the majority $(65.4$ per cent.) are traumatic lesions at various

TABLE III

Traumatic Lesions

\begin{tabular}{|c|c|c|c|c|c|}
\hline & $\begin{array}{l}\text { Servicemen } \\
\text { and } \\
\text { Pensioners }\end{array}$ & Civilians & Total & \multicolumn{2}{|c|}{ Percentage } \\
\hline $\begin{array}{l}\text { Cervicals } \\
\text { Complete } \\
\text { Incomplete }\end{array}$ & $\begin{array}{l}36 \\
86\end{array}$ & $\begin{array}{r}99 \\
245\end{array}$ & $\begin{array}{l}135 \\
331\end{array}$ & $23 \cdot 6$ & $\begin{array}{r}6.8 \\
16.8\end{array}$ \\
\hline $\begin{array}{l}\text { TI-5 } \\
\text { Complete } \\
\text { Incomplete }\end{array}$ & $\begin{array}{l}62 \\
18\end{array}$ & $\begin{array}{l}84 \\
27\end{array}$ & $\begin{array}{r}\text { I } 46 \\
45\end{array}$ & $9 \cdot 8$ & $\begin{array}{l}7 \cdot 5 \\
2 \cdot 3\end{array}$ \\
\hline $\begin{array}{l}\text { T6-I2 } \\
\text { Complete } \\
\text { Incomplete }\end{array}$ & $\begin{array}{l}\text { I } 98 \\
\text { II } 3\end{array}$ & $\begin{array}{l}4 \text { I9 } \\
\text { II } 5\end{array}$ & $\begin{array}{l}617 \\
228\end{array}$ & $43 \cdot I$ & $\begin{array}{l}3 \mathrm{I} \cdot 4 \\
\mathrm{II} \cdot 7\end{array}$ \\
\hline Cauda equina & 240 & $22 \mathrm{I}$ & $46 I$ & $23 \cdot 5$ & $23 \cdot 5$ \\
\hline Total & 753 & 1210 & 1963 & $100 \cdot 0$ & $100 \cdot 0$ \\
\hline
\end{tabular}


levels (Table II). The column headed 'Miscellaneous' consists of non-traumatic patients other than transverse myelitis and polios such as thrombosis of the spinal artery, haematomyelia, tuberculosis, tumours, syphilis, epidural abscesses, degenerative and congenital processes. It also includes mishaps after surgical procedures. Table III shows an analysis of the 1963 traumatic lesions according to the level of the lesions. Already at the time of that statistic there was a relatively high percentage of cervical injuries. This percentage has further increased, and a later statistic published in 1964 on 2780 traumatic lesions of all levels showed 506 or 24.4 per cent. tetraplegics. In the majority, spinal cord injuries occurred between the ages of 16 and 35 and the two major causes are road accidents, by motor-car and motor-cycle, and sports accidents, in particular diving into shallow water.

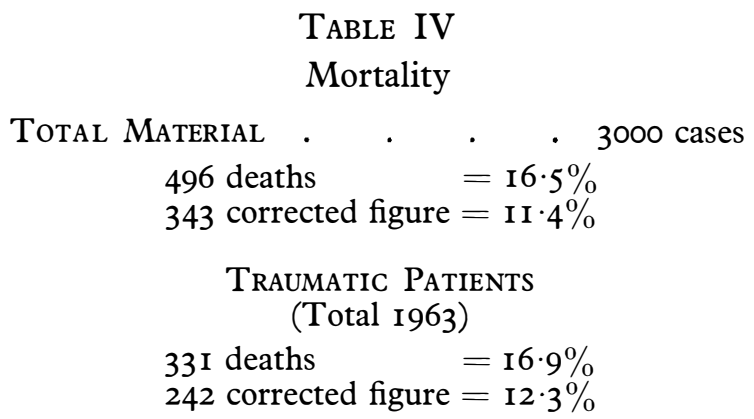

Servicemen And Pensioners

(Total 753)

I80 deaths $\quad=23.9 \%$

132 corrected figure $=17 \cdot 5 \%$
Civilians

(Total I2IO)

$$
\text { I } 5 \text { I deaths } \quad=\mathrm{I} 2.5 \%
$$$$
\text { I IO corrected figure }=9.0 \%
$$

Analysis of Servicemen and Pensioners

WORLD WAR I

(Total 67)

$$
39 \text { deaths } \quad=58 \cdot 2 \%
$$$$
\text { I } 5 \text { corrected figure }=22 \cdot 4 \%
$$

WORLD WAR II

(Total 468)

$$
\text { I25 deaths }=26 \cdot 7 \%
$$$$
\text { IO3 corrected figure }=22 \cdot 0 \%
$$

$$
\begin{aligned}
& \text { Post-war Period from } 1946 \\
& \text { (Total 2I8) } \\
& \text { I6 deaths } \quad=7 \cdot 3 \% \\
& \text { I } 4 \text { corrected figure }=6.4 \%
\end{aligned}
$$

The mortality rate amongst the 3000 patients is given in Table IV. These statistics include every patient who died either during treatment in this centre or after discharge home or in other institutions. The uncorrected figures include causes of death unrelated to paraplegia such as tuberculosis, cancer, cerebral haemorrhage, etc. These statistics revealed a very low mortality rate of both ex-servicemen and civilians admitted after World War II but even amongst the traumatic paraplegics from World War II, so many years after injury.

Since I947 I have published statistics at regular intervals on the domestic 
and industrial resettlement of paraplegics and the number engaged in remunerative work has varied between 69 and 82 per cent. of those discharged from the Centre and who were available for employment, the majority being full-time employed. Table $\mathrm{V}$ gives an analysis of the employment of 2012 patients, out of a total of

\section{TABLE V}

Employment Statistics on 3000 Patients

ANALYSIS

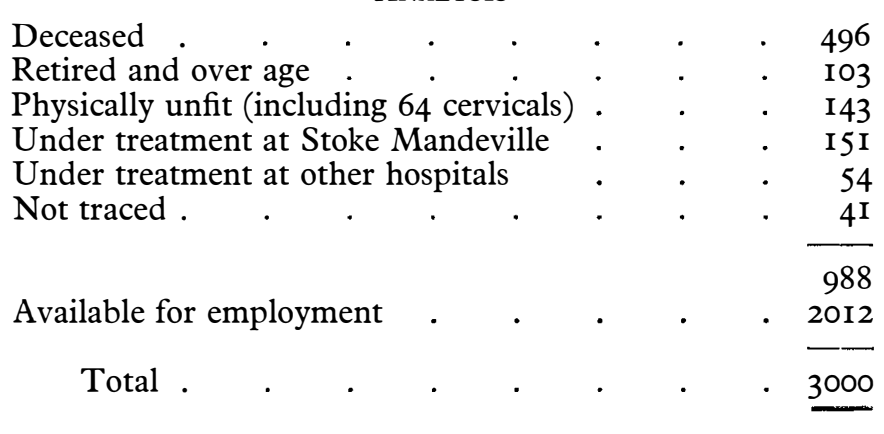

Available for EMPLOyMENT 2012

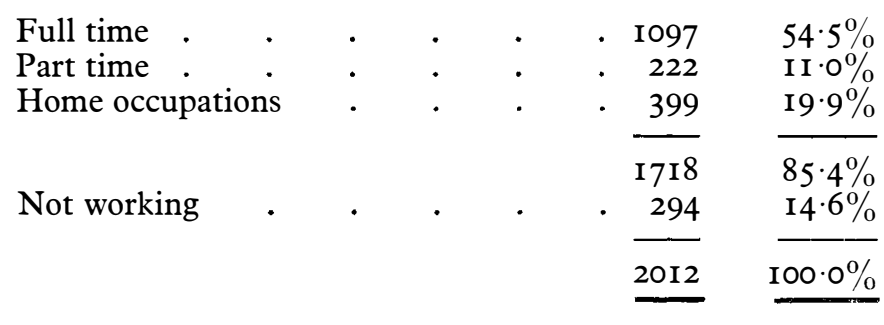

ANALYSIS OF EMPLOYED

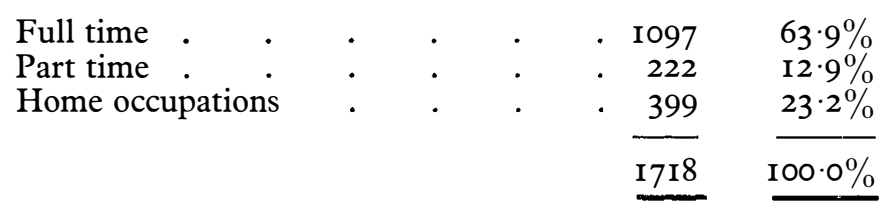

3000, available for employment at the time of the latest statistics in 1963 from which it will be seen that altogether 85.4 per cent. are gainfully employed, and of these 54.5 per cent. full time, in a variety of jobs, i.e. business, professional and open industry. Table VI demonstrates the employment statistics according to the levels of the lesions. Table VII shows the domestic resettlement of the survivors of the 3000 patients, from which it is clear that the great majority are living in their own homes, which have been adjusted to their disability either privately or by the local authorities. This includes the building of garages for their motor vehicles. 
TABLE VI

Statistics on 2012 Patients available for Employment

\begin{tabular}{|c|c|c|c|c|c|c|}
\hline & & $\begin{array}{l}\text { Full } \\
\text { time }\end{array}$ & $\begin{array}{l}\text { Part } \\
\text { time }\end{array}$ & $\begin{array}{l}\text { Home oc- } \\
\text { cupations }\end{array}$ & $\begin{array}{c}\text { Not } \\
\text { working }\end{array}$ & Total \\
\hline \multicolumn{7}{|l|}{ Cervicals } \\
\hline Complete & - & 9 & 13 & 37 & I & 60 \\
\hline Incomplete & - & 84 & $3 I$ & 89 & 27 & $23 \mathrm{I}$ \\
\hline \multicolumn{7}{|l|}{ T I -5} \\
\hline Complete & - & 77 & 20 & I9 & I4 & 130 \\
\hline Incomplete & . & 43 & 7 & I4 & 6 & 70 \\
\hline \multicolumn{7}{|l|}{ T 6-I2 } \\
\hline Complete & - & 270 & 75 & I I4 & 106 & 565 \\
\hline Incomplete & . & 206 & 20 & 43 & 64 & 333 \\
\hline Cauda equina & . & 277 & 35 & 52 & $6 I$ & 425 \\
\hline Polio . & . & 99 & 6 & I6 & 4 & I I 5 \\
\hline Miscellaneous & . & 32 & I5 & I 5 & I I & 73 \\
\hline Total & . & 1097 & 222 & 399 & 294 & 2012 \\
\hline Percentage & - & $54 \cdot 5$ & I I & I9.9 & $14 \cdot 6$ & 100 \\
\hline
\end{tabular}

\section{TABLE VII}

Domestic Resettlement of 3000 Patients

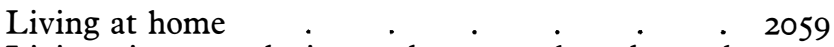

Living in paraplegic settlements, hostels and homes for the disabled . . . 240

Patients under treatment at Stoke Mandeville . I5 I

Patients under treatment in other hospitals . $\quad 54$

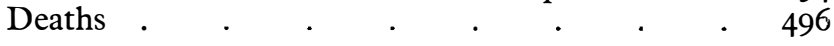

Routine After-care following Discharge. A systematic out-patient service was organised to deal with routine clinical check-ups for the increasing number of patients discharged to their homes and other institutions, in particular, for those who had found employment and were anxious to have as little time off work as possible. This has proved to be a most essential part of our work in 
detecting and treating any deterioration in a paraplegic's condition and thus keeping as many of them as possible at their work. Table I shows a very great increase in this after-care service over the years between I95I and 1962, and which is still continuing commensurate with the steadily increasing number of survivors. When distance prevents an out-patient check-up the paraplegic or tetraplegic is readmitted for a day or two for the necessary check-up.

Research. From the beginning, intensive clinical and experimental research has gone hand in hand with the clinical work. Research workers from this country and abroad have visited the Centre and some of them co-operated in research on certain physiological problems of the spinal man. It is beyond the scope of this survey to give details of the many research problems which have been dealt with throughout the years. The results of the research have been published in well over IOO publications in many leading journals, including monographs and chapters in textbooks (see References).

Meetings of medical and scientific organisations such as the Neurological and Orthopaedic Section of the Royal Society of Medicine, the British Biochemical Society, the British Society of Biological Engineering and Sections of International Congresses have been held at the Centre throughout the years. Regular International Scientific Meetings of Paraplegia have been held since I954 on the occasion of the Annual International Stoke Mandeville Games. As a result of these meetings the International Medical Society of Paraplegia was founded in I96I at Stoke Mandeville, which has its own international journal published by E. \& S. Livingstone of Edinburgh.

Teaching. Throughout the years the Centre has been engaged in teaching undergraduates and post-graduates of the medical profession as well as nursing, physiotherapy, and occupational therapy professions, and this activity has immensely increased in recent years:

I. Medical Staff, Welfare Officers and Administrators. Physicians, surgeons and medical students as well as administrators have visited the Centre from many hospitals in this country and abroad, and the Centre takes part in the regular post-graduate courses arranged by the British Council, organised by the Royal National Orthopaedic Hospital Stanmore, Middlesex, the National Hospital for Nervous Diseases, Queens Square, London, the Royal College of Surgeons and Medical Services of the Army and Air Force, and Administrative Medical Officers of the Ministry of Pensions and Social Insurance, Ministry of Labour, as well as Regional Hospital Boards of the Health Service.

2. Post-graduate Courses for Nurses. Apart from regular visits of groups of nurses sent to the Centre for formal lectures from the Royal College of Nursing, three-monthly Post-Graduate Courses have been introduced since I953 which are attended by nurses from this country and from all over the world. Some of these post-graduate nurses continue working in the Centre after the course to gain more detailed experience. The Centre is also included in the training programme of student and pupil nurses of the Aylesbury Nursing School.

3. Physiotherapy and Occupational Therapy Staff. In addition to full-day visits of individuals and groups of physiotherapists and occupational therapists from teaching schools, annual post-graduate courses for physiotherapy are held 
which have become quite popular and are greatly supported by the British Chartered Society of Physiotherapy.

4. Teaching outside the Centre. Throughout the years, members of the medical and physiotherapy staff as well as the lay administrator and welfare officer of the Centre have given very great number of lectures to teaching hospitals, training schools, Government departments and many other organisations.

Members of the medical staff have been invited to lecture at International Congresses and visited other countries to lecture on the problems of paraplegia.

Sport. Since the inception of the Stoke Mandeville Centre, sport has played a very important part in the physical, psychological as well as social rehabilitation of the paralysed, and the profound value of sport in preventing these patients from retiring into inactivity cannot be exaggerated. As I have already pointed out, sporting activities are included in the medical treatment and this has encouraged many patients to continue sport for their physical well-being and recreation after discharge from hospital. Interest and enthusiasm in competitive sport increased steadily, and in I 948 the Stoke Mandeville Games were founded as a sports movement for the paralysed. These Games, which at first were held annually as a national event, have developed since 1952 into the first organised annual sports festival for severely disabled people in the world. A Paraplegic Sports Endowment Fund founded with voluntary contributions has become responsible for financing the Games and has built throughout the years accommodation and sports facilities such as basketball pitches, bowling greens, etc., on the sports ground of Stoke Mandeville Hospital. The most recent development is the permission from the authorities of the National Health Service to build the first indoor sports stadium for disabled sportsmen, women and children in this country and, indeed, the world. The idea of sport for the disabled has spread all over the world, and the International Stoke Mandeville Games are held annually at Stoke Mandeville, but every fourth year in the country and place where the Olympic Games take place. Thus these Games have become the equivalent of the Olympic Games for the Paralysed.

As off-shoots of these Games the British Commonwealth Paraplegic Games and, more recently, the Pan-American Paraplegic Games have been founded. Moreover, for some years annual sports events have also been organised by other spinal units in this country and abroad. Sports clubs have been founded in many parts of the country by the paralysed and others severely physically handicapped themselves, and they meet regularly for training and play throughout the year.

Sports organisations for the able-bodied have taken a great interest in the development of the Stoke Mandeville Games. In 1956, during the Olympic Games in Melbourne, the International Olympic Committee awarded the Fearnley Cup, an Olympic Award presented for outstanding achievement in the service of the Olympic idea, to the organisation of the Stoke Mandeville Games. There could have been no better evidence of the dramatic change which has taken place in the whole concept of paraplegia than this recognition of paraplegic sportsmen and women by society. 


\title{
REFERENCES
}

Guttmann Ludwig (194I). Proc. Roy. Soc., 35, 305-308.

- (1945). New hope for spinal cord sufferers. N.Y. med. Times, $73,318$.

(1953). The treatment and rehabilitation of patients with injuries of the spinal cord. Monograph in Vol. Surgery, Medical History of the Second World War, pp. 422-516.

London: H.M. Stationery Office. (See previous references on management and research.)

(1954). Visceral activity and peripheral circulation in the spinal man. Ciba Foundation Symposium on Peripheral Circulation, pp. 192-203. (See previous references on research.) London: Churchill.

- (1962). Sport and the disabled (see previous references on sport). Sports Medicine, pp. 367-39i. London: Arnold.

- (1962). Our paralysed fellowmen at work. Rehabilitation, 43, 9-I7.

- (1965). Services for the treatment and rehabilitation of spinal Paraplegics and tetraplegics in Great Britain. Trends in Social Welfare, pp. 319-336. Pergamon Press.

\section{THE SPINAL CORD INJURY CENTER OF THE VETERANS ADMINISTRATION HOSPITAL, LONG BEACH, CALIFORNIA, U.S.A.}

\section{Facts and Thoughts}

By ERNest Bors, M.D.

\begin{abstract}
From The Spinal Cord Injury Service of the Veterans Administration Hospital, Long Beach, California, and the Department of Surgery of the University of California at Los Angeles, Los Angeles, Calif. 90024
\end{abstract}

SIR Ludwig GutTManN invited me to prepare this report. It should be stressed that the views and opinions expressed in this paper are my own and do not reflect those of the Veterans Administration of the United States. However, I should like to state that the Veterans Administration has had great foresight and vision in permitting the development of its eight centres according to the needs and potentials of the areas in which they are located. Thus, units were created based on a loose table of organisation rather than on strict uniformity.

Because of this freedom, our unit at Long Beach has enjoyed a great deal of autonomy, although occasionally the clash of the two philosophies can be felt which today encompasses medical education in general, namely the struggle of treating disease by entity rather than by department. The development of modern medicine makes teamwork necessary and functions of departments may overlap. To quote an example: renal transplantations require a team of internists, immunologists and surgeons. In some places the surgical sub-team consists of a vascular and urological surgeons, in others the urologists do all the necessary surgery. Thus, borderlines between departments or divisions are slowly vanishing and a more catholic approach is resurging, reminiscent of the times 50 years ago when sub-specialties were just emerging. This approach applies, in my opinion, also to the management of a spinal cord injury unit. 